\title{
La Imagen en la Enseñanza de las Ciencias: Algunos Resultados de Investigación en la Universidad de Granada, España
}

\author{
Francisco J. Perales \\ Universidad de Granada, Facultad de Ciencias de la Educación, Dpto. Didáctica de las Ciencias \\ Experimentales, Campus Universitario de Cartuja, 18071 Granada-España (e-mail: \\ fperales@ugr.es)
}

\begin{abstract}
Resumen
Se fundamenta y propone desarrollar una línea de investigación de creciente interés en la Didáctica de las Ciencias, como es el uso educativo de la imagen en sus distintos formatos. Se presentan algunos resultados relevantes de diversos estudios llevados a cabo por un grupo de trabajo de la Universidad de Granada en España. En ellos se resalta la necesidad de clasificar las imágenes empleadas en los libros de texto, mejorar su generalizada inadecuación didáctica y clarificar los requisitos cognitivos para su correcta comprensión. Por otra parte, se estudia la utilidad de la imagen como instrumento de modelización y la evaluación de programas de simulación por ordenador. Finalmente, también se evidenció la potencialidad educativa de los dibujos animados en la enseñanza de la Física.
\end{abstract}

\section{Image in Science Education: Some Results of the Research done at the University of Granada, Spain}

\begin{abstract}
A research subject of growing interest in Science Education such as the use of images in different formats is discussed and analyzed. Some relevant results of different studies carried out by a research group of the University of Granada in Spain are presented. The necessity of classifying the images used in textbooks, to improve their generalized misuse in teaching, and to clarify the cognitive requirements for their good comprehension, is underlined. Also, the utility of the image as a means of modeling and the evaluation of computer simulation programs are studied. Finally, it is also pointed out the educational potential of cartoons for the teaching of Physics.
\end{abstract}

Keywords: image, science education, modeling, textbook, computer simulation 


\section{INTRODUCCIÓN}

Enseñar ciencias, no cabe duda, es un asunto complejo, se podría decir que tanto o más complejo que el propio proceso de la investigación científica. Algunas evidencias, entre otras, serían:

- La enseñanza de las ciencias debe trasladar los cambios experimentados por el conocimiento científico, cada día mayor en cantidad y calidad.

- Debe mostrar la naturaleza de la ciencia que se trata de enseñar.

- Trabaja con seres humanos (profesores y alumnos), con instituciones (escuelas), en contextos socioeconómicos diversos, etc., todos ellos mucho más cambiantes e incontrolables que la mayoría de los objetos que investiga la Ciencia.

- Los medios y recursos disponibles suelen ser escasos y heterogéneos.

- No suele existir un itinerario formativo bien establecido y eficaz para el profesorado.

A todo ello habría que sumar que las reglas que regulan la enseñanza de las ciencias están mucho menos explicitadas y consensuadas que las que lo hacen sobre la indagación científica, asentada habitualmente en empresas o universidades, donde, aunque imperfectos, suelen existir unos mecanismos de acceso, regulación del procedimiento de trabajo y control de calidad.

Parece pues que la enseñanza de las ciencias cuenta con unas condiciones de partida claramente desfavorables frente a la investigación. A las ya mencionadas habría que añadir la difícil adaptación de la primera a los cambios sociales en los que se haya inmersa y, en concreto, se refiere a la llamada "sociedad de la información". Mientras que la investigación científica suele situarse a la vanguardia en la utilización de la tecnología (medios informáticos, instrumentos de medida, etc.), las instituciones educativas son máquinas con un elevado grado de inercia que les dificulta su permeabilidad a los avances científico-tecnológicos.

Una de las características de la mencionada sociedad de la información es el peso jugado por el uso de la comunicación en formato icónico frente al lenguaje verbal. Nuestros jóvenes pueden ser denominados "ciberestudiantes" frente a los "libroestudiantes" de antaño (Carney y Levin, 2002). La televisión, la publicidad, los teléfonos móviles, Internet, etc., muestran imágenes de forma intensiva para informar, entretener o persuadir, y no sólo unidireccionalmente: el intercambio, producción y manipulación de las imágenes está también al alcance de casi cualquier ciudadano. Además, la interpretación de imágenes posee un interés de primera magnitud en algunas de las profesiones actuales como las biomédicas (p. ej., ecografías, radiografías, etc.), las Ciencias de la Tierra (mapas geológicos), Arte, etc.

Pero, ¿en qué medida estos profundos cambios en la generación y difusión de la información en nuestra sociedad actual se han trasladado a nuestras aulas? Sin ánimo de pretender una excesiva generalización, podríamos afirmar que demasiado lentamente. Aún reconociendo que en algunas de ellas las TICs van asentándose y que vamos sustituyendo progresivamente la pizarra por transparencias o presentaciones de ordenador con multiplicidad de ilustraciones, videos, etc., se dista mucho del aprovechamiento del potencial que el uso de la imagen puede aportar a la enseñanza, en general, y de las ciencias, en particular. Donde en apariencia este cambio resulta más visible es en el formato de los libros de texto, especialmente en los ámbitos de la educación obligatoria; en concreto sus páginas se han llenado de ilustraciones y de colorido. Ahora bien, ¿son estos nuevos formatos adecuados para lograr un mejor aprendizaje de las ciencias? y, por otra parte, ¿debemos conformarnos con estos cambios cuasiestéticos como unos de los escasos efectos visibles del potencial educativo de las imágenes para nuestras aulas?

El objetivo del presente estudio es poner de manifiesto las diversas facetas que presenta la utilización de la imagen en la enseñanza y aprendizaje de las ciencias y, en segundo término, ejemplificar diferentes investigaciones llevadas a cabo por el grupo de trabajo de la Universidad de Granada y que tratan de incidir en algunas de ellas. 


\section{MARCO TEÓRICO}

En primer lugar se debería construir una posible estructura de las relaciones Imagen-Didáctica de las Ciencias. Para ello se ha elaborado la Fig. 1 que recoge, en forma de mapa conceptual, los distintos formatos de la imagen y sus usos en la Educación Científica. Dicha figura servirá como guía para el desarrollo de este trabajo, tanto en la propia fundamentación teórica como en los resultados de las investigaciones que se presentarán.

Dada la generalidad del término imagen y de su poder comunicativo, se puede comprender la dificultad de establecer un marco teórico universal para entender su papel en la enseñanza de las ciencias. Disciplinas como el Arte, la Semiótica, el Marketing o la Psicología disponen de sus propias reglas o elaboraciones teóricas donde tratar de prescribir, explicar o interpretar dicho papel. Es por ello que, aun reconociendo las limitaciones que ello supone, la revisión del marco teórico se centrará en el seno de la propia Didáctica de las Ciencias Experimentales (para una revisión más amplia desde una perspectiva más interdisciplinar puede consultarse Perales, 2006), marco que podría agruparse bajo la denominación de lo que Mathewson (1999) ha denominado "pensamiento visoespacioal". Para ello se van a ir desarrollando algunas de las aportaciones teóricas utilizando como guía los tópicos de la Educación Científica indicados en la Fig. 1.

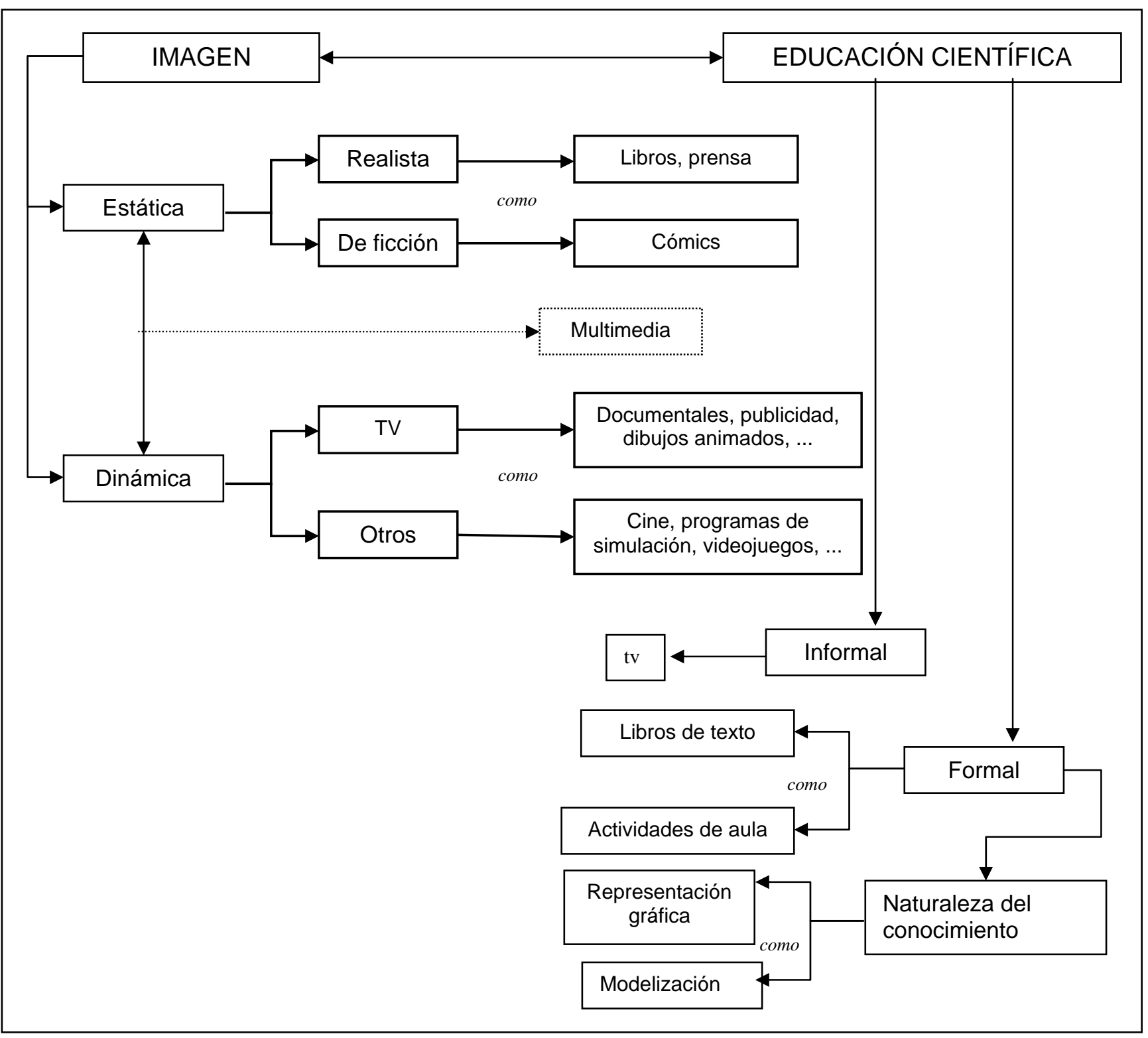

Fig. 1: Mapa conceptual propuesto para las relaciones imagen-educación científica (Adaptado de Perales, 2006). 


\section{a) Educación Formal}

Una de las herramientas básicas en la construcción de la Ciencia y de su enseñanza es la modelización. En el primer caso sirve para la elaboración de descripciones, explicaciones y predicciones sobre la Naturaleza de un modo simplificado, de manera que permita su intercambio y debate dentro de la comunidad científica (p. ej., los sucesivos modelos atómicos); en el segundo caso se trata de la generación de los modelos por los propios estudiantes, lo que les permitiría comprender el proceso seguido por los científicos y las reglas que lo rigen como forma de aproximarse al conocimiento establecido. En ambos casos la dimensión gráfica puede ser útil por su carácter simbólico y sintético, debiéndose tomar en consideración los sistemas de representación habituales (p. ej., el símbolo flecha), aunque desde un punto de vista crítico y sin descartar su modificación o sustitución por otros (Jiménez y Perales, 2001a). No obstante, se ha de procurar siempre, especialmente en el caso de la enseñanza de esos modelos, establecer una clara separación entre la realidad que se pretende representar, la teoría elaborada para explicarla (el propio modelo en nuestro caso) y los símbolos elegidos para hacerlo (Lemeignan y WeilBarais, 1993; Jiménez y Perales, 2002).

Mención aparte merece un tipo de imagen muy utilizado en el ámbito científico, como es el de las gráficas, estudio realizado por Shah y Hoeffner (2002). Como se sabe, aquellas constituyen una representación de la dependencia entre variables mediante funciones matemáticas. Permiten transformar una información cuantitativa (p. ej., una tabla de datos) en otra más fácilmente comprensible, aunque también pueden inducir a errores cuando carecen de algunos elementos informativos. Con relación a los factores que pueden influir en una correcta interpretación de las gráficas por los lectores, identifican tres factores principales: las características de la representación visual (tipo de gráfica, color, etc.), el conocimiento sobre gráficas disponible por el lector y el contenido al que se refiere la gráfica (p. ej., edad vs. peso). En cuanto al diseño de gráficas, los autores proponen los siguientes principios:

1. Elegir el formato de gráfica en función del objetivo de la comunicación (p. ej., gráficas de línea para tendencias).

2. Utilizar formatos múltiples para comunicar los mismos datos.

3. Utilizar las "mejores" dimensiones visuales para expresar información métrica siempre que sea posible.

4. Usar la animación con precaución.

5. Reducir las demandas de la memoria de trabajo, esto es, la cantidad de información contenida en la gráfica.

6. Elegir los colores cuidadosamente.

7. La "tercera" dimensión es adecuada a menos que se necesite información métrica precisa.

8. Elegir cuidadosamente las proporciones y la densidad de datos (tamaño de la gráfica).

9. Hacer consistentes las gráficas y el texto (guiar la interpretación de la gráfica a través del texto).

Siguiendo con el marco conceptual representado en la Fig. 1 y, en concreto, en el contexto de la Educación Formal, el libro de texto continúa jugando un papel de primer orden, tanto en la educación obligatoria como en la postobligatoria. Tal como se señalaba en la Introducción, su aspecto externo ha cambiado profundamente a lo largo de los últimos años, dotándose de un uso intensivo del color y ganando espacio las ilustraciones en detrimento del texto escrito, llegando a ocupar hasta el 50 por ciento de la superficie impresa del mismo. A pesar de ello el interés que ha suscitado estos crecientes formatos comunicativos se halla lejos de su masiva presencia.

Los principales núcleos de investigación en torno a las imágenes de los libros de texto son los siguientes:

- Las características que poseen las mismas y su posible categorización, tanto intrínsecas como en relación al texto escrito (Perales y Jiménez, 2002; Pérez de Eulate et al., 1999).

- Su papel diferenciado, en comparación con el texto escrito, dentro de la estructura didáctica del libro (Jiménez y Perales, 2001a).

- Los requerimientos de habilidades específicas, por parte de los alumnos, que demanda su interpretación (Pandiella y Perales, 2007). 
- El papel que desempeñan como medio de representación de analogías (Thiele y Treagust, 1995).

Se analizará ahora el uso de la imagen en las actividades de aula. Como cabe suponer, este apartado permite una gran diversidad de actuaciones de distinto grado de generalidad, tales como:

- La generación de imágenes por parte de los alumnos, p. ej., a partir de la predicción de lo que esperan ver o de la propia observación de preparaciones microscópicas (Díaz de Bustamante y Jiménez, 1996) o para modelizar situaciones físicas (Gutiérrez, 1999; Jiménez, 1998).

- La utilización de las imágenes para la detección de sus ideas alternativas (Aguilar et al., 2007).

- Las dificultades que encuentran aquellos al leer imágenes (Pintó, 2002; Pintó y Ametller, 2002).

- Las condiciones bajo las cuales las imágenes podrían convertirse en fuentes de aprendizaje (Mottet, 1996).

- El efecto de las ilustraciones incluidas en un texto en relación con el tipo de preguntas para evaluar el aprendizaje adquirido (Balluerka, 1995).

- La comparación entre una enseñanza con medios tradicionales y otra en donde se hace un uso intensivo de imágenes estáticas y dinámicas (Otero et al., 2003).

- La evaluación educativa de programas de simulación por ordenador (Sierra, 2003).

- El uso de programas disponibles en Internet para modelizar fenómenos físicos a partir de grabaciones con "web cam" (Ezquerra, 2005).

- El papel pedagógico que los profesores asignan a las imágenes de los libros de texto (Fanaro et al., 2005).

\section{b) Educación Informal.}

Se conoce por Educación Informal la que se produce sin una intencionalidad específica, interviniendo canales como los medios de comunicación de masas, la publicidad estática, conversaciones, etc. (véase, p. ej. Sadler, 2004). Por su impacto, se observará la influencia de la TV en la educación científica informal. Los estudios en este ámbito son, sin embargo, escasos; algunos de ellos tratan de:

- La utilización de diferentes programas de televisión para evaluar su incidencia en la comprensión de la naturaleza de la ciencia (Dhingra, 2003).

- Los valores que aquellos pueden transmitir en los jóvenes (Kim, 1994).

Para finalizar se tratará de sintetizar los resultados de las investigaciones anteriores en una serie de pautas:

- La modelización como herramienta de construcción del conocimiento científico y del binomio enseñanza-aprendizaje constituye una poderosa fuente de oportunidades para una utilización dinámica de las imágenes, sea en su papel de medio de representación del conocimiento o en el de su generación por parte de los estudiantes. No obstante, deben satisfacerse algunas condiciones básicas para que se convierta en un instrumento educativo eficiente y que tienen que ver especialmente con su reconstrucción en el aula y con la separación de los planos real, teórico y simbólico.

- La gran frecuencia y variedad de tipos de imágenes -incluidas las que utilizan el formato televisivo- con potencial educativo exige una rigurosa clasificación de las mismas que permita seleccionar y aprovechar sus valores específicos para los diferentes objetivos que se pretendan. Hay que resaltar que las imágenes no pueden convertirse en meros objetos decorativos o de observación pasiva, exigen un trabajo explícito sobre ellas, tanto en su diseño como por parte de los estudiantes, para lo cual las TICs facilitan cada día más esta tarea.

- El trabajo de aula con imágenes no puede obviar la relación con el texto escrito u oral, con el cual debe conformar una unidad.

- Las imágenes pueden ser beneficiosas para el aprendizaje individual siempre que reúnan algunos requisitos que tienen que ver con la información que suministren, la complejidad de su 
interpretación, la metodología didáctica o los conocimientos, habilidades y actitudes previas de que dispongan los lectores.

- Este campo pedagógico no es adquirido espontáneamente por el profesorado responsable de llevarlo al aula, se hace precisa por tanto una formación específica en el uso de las imágenes, sea de forma presencial, semipresencial o virtual.

\section{RESULTADOS Y DISCUSIÓN}

Una vez que se han presentado algunas de las líneas de investigación que, desde la Didáctica de las Ciencias Experimentales, se han venido desarrollando en torno al tópico de este trabajo, se van a presentar ahora los principales resultados que se han obtenido por el grupo de trabajo relacionados con el mismo. Al respecto se pueden plantear algunas preguntas que originaron las distintas investigaciones:

a) ¿Cómo son las imágenes (incluidas las gráficas) presentes en los libros de texto de Física y Química españoles para la Educación Secundaria? ¿Son adecuadas desde el punto de vista didáctico? ¿Qué demanda cognitiva poseen? ¿Son correctamente comprendidas e interpretadas por los estudiantes?.

b) ¿Se pueden generar imágenes para la modelización de fenómenos físicos a partir de una análisis crítico de las mismas? ¿Son compatibles con un trabajo en el aula más eficiente?

c) ¿Cumplen adecuadamente unos criterios de calidad educativa los programas de simulación en Física? ¿Pueden ser mejorados en el contexto habitual de aula? ¿Qué metodologías docentes pueden ser adecuadas en dicho contexto?

d) Dentro de la categoría de programas televisivos de ficción conocida como "dibujos animados", ¿pueden emplearse para la enseñanza de la Física?

Dar respuesta a estas preguntas exigió desarrollar distintos enfoques de investigación (cualitativos/cuantitativos) con diversas muestras de alumnos e instrumentos de recogida de datos. Dadas las limitaciones de espacio de que disponemos, remitimos al lector a consultar las fuentes originales para conocer tal información, ahora se destacarán los resultados más relevantes obtenidos en las investigaciones emprendidas.

a) Se comenzará por la respuesta hallada a las dos primeras cuestiones. La abundancia y diversidad de imágenes presentes en los libros de texto actuales exige un análisis de las mismas partiendo de un sistema clasificatorio (taxonómico) bien fundamentado. Una comparación de algunos de ellos (Matus et al., 2008) parece avalar la 'bondad' del propuesto por nosotros (Perales y Jiménez, 2002) que tiene en cuenta la función didáctica de la imagen, su distinta iconicidad, su relación con el texto escrito y el contenido científico subyacente. Por otra parte, la especificidad de las imágenes conocidas como "gráficas" exige un sistema descriptivo propio adaptado a partir del sistema clasificatorio mencionado y desarrollado por García y Cervantes (2004).

La aplicación de la taxonomía referida a una amplia muestra de libros españoles de Educación Secundaria aportó unos resultados que, a grandes rasgos, evidencian una inadecuación didáctica de la mayoría de las ilustraciones presentes en los libros de texto analizados, identificada a partir de algunas de las siguientes características que se verifican de un modo total o parcial:

- Intencionalidad meramente decorativa y, por tanto, prescindible.

- Excesiva complejidad, que impide centrarse en la información esencial frente a la accesoria o adaptarse al conocimiento previamente disponible por el lector.

- Insuficiente orientación sobre la información que suministran (o debieran suministrar), tanto dentro de la propia imagen como en relación con el texto escrito externo a la misma.

- Indistinguibilidad de elementos simbólicos (y, por tanto, convencionales) y realistas.

- No explotación de la función analógica de las imágenes o utilización inadecuada de la misma en cuanto a las reglas que deben regir la relación entre el contenido original y el utilizado como análogo.

- No vinculación al contexto científico (p. ej., como resultado de un proceso de modelización) y/o cotidiano. 
- Ausencia de actividades explícitamente diseñadas para el trabajo con imágenes.

- Presencia de algunos errores científicos y/o técnicos que ponen de manifiesto la descoordinación entre los autores del texto escrito y del icónico.

Si ahora se trata de responder a la tercera cuestión, esto es, a la demanda cognitiva de las imágenes, habría que intentar describir las habilidades que su comprensión demanda por parte de los alumnos y comprobar si difieren sustantivamente de las que requiere el texto escrito de los libros de texto. Ello implica disponer de una clasificación adecuada de dichas habilidades. En la investigación diseñada al efecto (Pandiella y Perales, 2007) con un libro de texto argentino, se evidenció la necesidad de prestar atención a esta importante dimensión de la representación del conocimiento y a su conexión con la representación textual.

Por último se hará referencia a la cuarta cuestión que, en esta ocasión, está referida a la comprensión de los estudiantes sobre las representaciones gráficas cartesianas en libros de texto de Química. El estudio realizado (García y Perales, 2007) permitió identificar qué aspectos de la información contenida en dichas imágenes son peor comprendidos por aquellos, sus posibles causas y las actividades que podrían mejorar dicha comprensión.

b) Tal y como se refirió anteriormente, la simbología adoptada en la modelización de los fenómenos naturales posee un carácter convencional y no siempre compatible con los modelos mentales de los alumnos. Ello condujo a analizar la simbología utilizada para la representación de las interacciones en Física y proponer una alternativa que intentara evitar errores en su interpretación, contrastándola posteriormente con las generadas por los propios alumnos (Jiménez y Perales, 2001b). El siguiente paso fue probar su efectividad en situaciones de aula mediante actividades de resolución de problemas. Los resultados obtenidos, a través de un complejo diseño de investigación, evidenciaron que, en general, los alumnos alcanzaban un mejor aprendizaje a medio y largo plazo (Jiménez, 1998), lo cual fue también confirmado por otros investigadores en un contexto diferente (Savinainen et al., 2005).

c) El tercer grupo de cuestiones tiene que ver con la eficiencia educativa de los programas de enseñanza de las ciencias mediante simulación por ordenador. Hoy día se pueden encontrar toda suerte de estos programas a través de Internet y con unas características técnicas progresivamente mejores. No obstante, existen escasos estudios que verifiquen sus posibilidades didácticas en situaciones de aula reales. Este fue el propósito de la investigación emprendida (Sierra, 2003). En ella se abordó el estudio de un programa 'ad hoc', el cual se fue modificando a fin de mejorar su capacidad técnica y la oferta educativa, tanto para el profesor como para el alumno; asimismo se evaluó un programa de gran difusión comercial, 'Interactive Physics'.

Los resultados obtenidos en diversos grupos de alumnos de Educación Secundaria y con distintos enfoques de investigación, muestran mejoras parciales en el conocimiento conceptual, procedimental y actitudinal para los estudiantes que siguieron una metodología de investigación dirigida y que utilizaron el programa de simulación 'ad hoc' (Sierra y Perales, 2003).

d) A pesar de la irrupción de Internet en la vida de muchos de nuestros estudiantes, la televisión continúa ejerciendo una poderosa influencia en su forma de vida y costumbres. Uno de los programas clásicos con mayor tradición e índice de audiencia entre los más jóvenes (y los menos también) son los 'dibujos animados'. Esas características fueron precisamente las que motivaron preguntarse acerca de su potencial educativo en el ámbito de la Física. El supuesto básico de partida para esta investigación fue que la naturaleza ficticia de los dibujos animados, y la consecuente violación de las leyes físicas que en ellos se evidenciaba, podría convertirse en un instrumento útil para favorecer el aprendizaje de la Física en alumnos de Educación Secundaria (Vilchez, 2004). Para ello se llevaron a cabo algunas experiencias de aula, como las siguientes:

- La identificación de secuencias imposibles desde el punto de vista físico, por parte de alumnos y profesores, cuando se les mostraban capítulos de dibujos animados.

- La justificación física, por parte de los alumnos, de cómo deberían haberse producido.

- La discusión en grupo de las mismas para tratar de llegar a una respuesta de consenso. 
- La conversión de estas secuencias en problemas físicos, a fin de vivenciar el proceso de construcción del enunciado de un problema.

- La inclusión del análisis de una secuencia de dibujos animados en el proceso de evaluación final de los alumnos.

Los resultados obtenidos lograron notables incrementos en algunos conocimientos, procedimientos y actitudes de los estudiantes participantes en las experiencias (Perales y Vilchez, 2005).

Por otra parte, se llevó a cabo un análisis de la imagen de la ciencia y de los científicos mostrada por un gran número de capítulos de dibujos animados, comparándola con la presente en cómics (Vilchez y Perales, 2006).

\section{CONCLUSIONES}

Son muchos los frentes abiertos y la escasez de investigación impide establecer afirmaciones concluyentes. A pesar de ello se pueden plantear algunas sugerencias de investigación que no deben ignorar los avances que se vayan logrando en otras disciplinas como la Psicología, la Semiótica, etc.

1. Priorizar las investigaciones en relación con los canales de información científica preferentes para nuestros alumnos, tales como los libros de texto, la televisión o Internet.

2. No se deben considerar las imágenes como meros objetos contemplativos, antes al contrario, se ha de trabajar sobre ellas observándolas, modificándolas, criticándolas, sustituyéndolas... La nueva sociedad de la información presente en la vida de nuestros jóvenes requiere una capacitación específica que desemboque en una verdadera alfabetización científico-visual acorde con su peso específico en dicha sociedad.

3. La gran diversidad de imágenes presentes en la educación formal e informal exige una rigurosa selección de las mismas en función de los objetivos educativos que planteados, sin descartar el uso de distintos tipos de imágenes para representar un mismo hecho científico.

4. Una de las principales funciones de las imágenes simbólicas en el conocimiento científico es la de constituir un medio de representación de dicho conocimiento a través del proceso de modelización, por lo que debiera potenciarse su uso teniendo presente una clara separación entre los planos real, teórico y simbólico. Ello implica recuperar las imágenes preexistentes pero también formas alternativas.

5. Existe una tendencia a sustituir la manipulación real de objetos por imágenes estáticas o dinámicas, entre las cuales los programas de animación o simulación poseen un protagonismo creciente. Su utilización puede ser didácticamente útil cuando se cumplen determinadas condiciones, pero siempre y cuando no constituyan la única fuente de aprendizaje en detrimento del contacto real del estudiante con su entorno.

6. Se hace preciso indagar de un modo exhaustivo en las 'ideas previas' que los estudiantes mantienen sobre los códigos gráficos empleados habitualmente en sus canales de información, y en los modos de reconducirlas en el caso de que difieran de las correctas.

7. La televisión y, por extensión, otras variantes interactivas como los videojuegos, pueden desempeñar una indudable función educativa en el aula, siempre y cuando sean analizados críticamente en su dimensión científica, aprovechando su indudable atractivo entre los jóvenes.

8. Por último debe resaltarse la necesidad de implementar y evaluar programas de formación del profesorado que les capacite en la aplicación de los diferentes usos educativos de la imagen. 


\section{REFERENCIAS}

Aguilar, S., C. Maturano y G. Núñez; Utilización de imágenes para la detección de concepciones alternativas: un estudio exploratorio con estudiantes universitarios, Revista Electrónica de Enseñanza de las Ciencias, ISSN: 1579-1513 (en línea) 6(3), 2007. http://www.saum.uvigo.es/reec. Acceso: 9 de Abril (2008).

Balluerka, N.; Cómo mejorar el estudio y aprendizaje de textos de carácter científico. Servicio de Publicaciones de la Universidad del País Vasco, Bilbao, España, pp. 63-67 (1995).

Carney, R.N. y H.R. Levin; Pictorial illustrations still improve students' learning from text, Educational Psychology Review: 14(1), 5-26 (2002).

Díaz de Bustamante, J. y M.P. Jiménez; ¿Ves lo que dibujas? Observando células con el microscopio, Enseñanza de las Ciencias: 14(2), 183-194 (1996).

Dhingra, K.; Thinking about television science: how students understand the nature of science from different program genres, Journal of Research in Science Teaching: 40, 234-256 (2003).

Ezquerra, A.; Utilización de videos para la realización de medidas experimentales, Alambique: 44, 113-119 (2005).

Fanaro, M.A., M.R. Otero y I.M. Greca; Las imágenes en los materiales educativos: las ideas de los profesores, Revista Electrónica de Enseñanza de las Ciencias, ISSN: 1579-1513 (en línea) 4(2), 2005. http://www.saum.uvigo.es/reec. Acceso: 19 de Octubre (2007).

García, J.J. y A. Cervantes; Las representaciones gráficas cartesianas en los libros de texto de ciencias, Alambique: 41, 99-108 (2004).

García, J.J. y F.J. Perales; ¿Comprenden los estudiantes las gráficas cartesianas usadas en los textos de ciencias? Enseñanza de las Ciencias: 25(1), 107-132 (2007).

Gutiérrez, R.; La causalidad en los razonamientos espontáneos, Enseñanza de las Ciencias: № extra, 31-61 (1999).

Jiménez, J.D.; Los medios de representación gráfica en la enseñanza de la Física y la Química, Tesis Doctoral, Dpto. de Didáctica de las Ciencias Experimentales, Universidad de Granada, Granada-España (1998).

Jiménez, J.D. y F.J. Perales; Graphic representation of force in secondary education: analysis and alternative educational proposal, Physics Education: 36, 227-235 (2001a).

Jiménez, J.D. y F.J. Perales; El análisis secuencial del contenido. Su aplicación al estudios de libros de texto de Física y Química, Enseñanza de las Ciencias: 19(1), 3-19 (2001b).

Jiménez, J.D. y F.J. Perales; Modélisation et representation graphique de concepts. Bulletin de I'Union des Physiciens: 96, 397-417 (2002).

Kim, D.L.; Captain Planet and the planeteers: kids, environmental crisis, and competing narratives of the new world order, Sociological Quarterly: 35(1), 103-120 (1994).

Lemeignan, G. y A. Weil-Barais; Construire des concepts en physique. Ed. Hachette Education. Col. Didactiques, París, Francia (1993).

Matus, L., A. Benarroch y F.J. Perales; Las imágenes sobre el enlace químico usadas en los libros de texto de Educación Secundaria. Análisis desde los resultados de la investigación educativa, Enseñanza de las Ciencias: 26(2), (2008) (en prensa).

Matthewson, J.H.: Visual-spatial thinking: An aspect of science overlooked by educators, Science Education: 83(1), 33-54 (1999). 
Mottet, G.; Images et activités scientifiques. Reintegrer l'image, Aster: 22, 3-13 (1996).

Otero, M.R., I.M. Greca y F.L.. Da Silveira; Imágenes visuales en el aula y rendimiento escolar en Física: Un estudio comparativo, Revista Electrónica de Enseñanza de las Ciencias, ISSN: 15791513 (en línea) 2(1), 2003. http://www.saum.uvigo.es/reec. Acceso: 19 de Octubre (2007).

Pandiella, S. y F.J. Perales; Skills involved in understanding science textbook illustrations. A case study, In Science Education in Focus by M. V. Thomase, Nova Science Publishers, Nueva York, USA (2007).

Perales, F.J.; Uso (y abuso) de la imagen en la enseñanza de las ciencias, Enseñanza de las Ciencias: 24(1), 13-10 (2006).

Perales, F.J. y J.D., Jiménez; Las ilustraciones en la enseñanza-aprendizaje de las ciencias. Análisis de libros de texto, Enseñanza de las Ciencias: 20(3), 369-386 (2002).

Perales, F.J. y Vilchez; J.M., The teaching of physics and cartoons: can they be interrelated in secondary education?, International Journal of Science Education: 27(14), 1647-1670 (2005).

Pérez de Eulate, L., E. LLorente y A. Andreu; Las imágenes de la digestión y excreción en los textos de primaria, Enseñanza de las Ciencias: 17(2), 165-178 (1999).

Pintó, R. (ed.); The science teacher training in an information society (STTIS) project, International Journal of Science Education: 24(3), special issue (2002).

Pintó, R. y J. Ametller; Students' difficulties in reading images. Comparing results from national research groups, International Journal of Science Education: 24(3), 333-341 (2002).

Savinainen, A., P. Scott y J. Viiri; Using a bridging representation and social interactions to foster conceptual change: Designing and evaluating an instructional sequence for Newton's third law, Science Education: 89(1), 175- 195 (2005).

Sadler, T.D.; Informal Reasoning Regarding Socioscientific Issues: A Critical Review of Research, Journal of Research in Science Teaching: 41(5), 513-536 (2004).

Shah, P. y J. Hoeffner; Review of graph comprehension research: Implications for instruction, Educational Psychology Review: 14(1), 47-69 (2002).

Sierra, J.L.; Estudio de la influencia de un entorno de simulación por ordenador en el aprendizaje por investigación de la Física en Bachillerato, Tesis Doctoral, Dpto. de Didáctica de las Ciencias Experimentales, Universidad de Granada, Granada-España (2003).

Sierra, J.L. y F.J. Perales; The effect of instruction with computer simulation as a research tool on open-ended problem solving in a Spanish classroom of 16-years-old, Journal of Computers in Mathematics and Science Teaching: 22(2),119-140 (2003).

Thiele, R.B. y D.B. Treagust; Analogies in chemistry textbooks, International Journal of Science Education: 17(6), 783-795 (1995).

Vilchez, J.M.; Física y dibujos animados. Una estrategia de alfabetización científica en la Educación Secundaria, Tesis Doctoral, Dpto. de Didáctica de las Ciencias Experimentales, Universidad de Granada, Granada-España (2004).

Vilchez, J.M. y F.J. Perales; Image of science in cartoons and its relationship with the image in comics, Physics Education: 41(3), 240-249 (2006). 